\title{
CONTROLE BIOLÓGICO EM PRAGAS DE Ilex paraguariensis (A. St.- Hil.) COM FUNGO Beauveria sp.
}

\author{
Herta Stutz Dalla Santa ${ }^{1}$; Nilton José Sousa ${ }^{2}$; Elaine Pittner ${ }^{3}$, Osmar Roberto Dalla Santa ${ }^{4}$; \\ Carlos Ricardo Soccol ${ }^{5}$ \\ ${ }^{1}$ Bióloga, Dr ${ }^{\mathrm{a}}$., Depto. de Engenharia de Alimentos, UNICENTRO, Guarapuava, PR, Brasil - hdalsanta@yahoo.com.br \\ ${ }^{2}$ Eng. Florestal, Dr., Depto. de Ciências Florestais, UFPR, Curitiba, PR, Brasil - nilton@ufpr.br \\ ${ }^{3}$ Bióloga, M.Sc., Depto. de Farmácia, UNICENTRO, Guarapuava, PR, Brasil - elpittner@ yahoo.com.br \\ ${ }^{4}$ Biólogo, M.Sc., Depto. de Engenharia de Alimentos, UNICENTRO, Guarapuava, PR, Brasil - ordallasanta@ yahoo.com.br \\ ${ }^{5}$ Eng. Químico, Laboratório de Processos Biotecnológicos, UFPR, Curitiba, PR, Brasil - soccol@ufpr.br
}

Recebido para publicação: 26/09/2007 - Aceito para publicação: 04/06/2008

\begin{abstract}
Resumo
O objetivo deste trabalho foi verificar a potencialidade de produção do fungo Beauveria sp. em resíduos agroindustriais, a manutenção da viabilidade dos esporos após secagem e armazenamento e sua patogenicidade em insetos de ocorrência na erva-mate: Thelosia camina e Hylesia sp. Utilizou-se a cepa LAG de Beauveria sp., isolada de uma lagarta Thelosia camina infectada. Os esporos foram produzidos em uma mistura de bagaço de cana-de-açúcar e batata-refugo (60-40\%) e utilizados para testes de secagem que resultaram em $76 \%$ de viabilidade após $24 \mathrm{~h} / 35^{\circ} \mathrm{C}$, com concentração de mais de $10^{9}$ esporos.g $^{-1}$ do material após armazenamento em temperatura ambiente durante 60 dias. Os experimentos de patogenicidade resultaram em índices de mortalidade que variaram de 15,9 a 97\%, de acordo com a forma de aplicação (imersão ou pulverização) e com a concentração utilizada (suspensões de $10^{8}$ a $10^{5}$ esporos. $\mathrm{mL}^{-1}$ ou suspensão de macerado de lagartas infectadas com o fungo); sendo essas aplicações feitas in vitro ou a campo. Este estudo possibilitou verificar e confirmar a patogenicidade da cepa Beauveria sp. sobre os lepidópteros na fase larval, como Thelosia camina e Hylesia sp., que pode ser usado como possível agente de controle biológico na cultura da erva-mate.

Palavras chave: Beauveria sp.; controle biológico; lagartas; erva-mate.
\end{abstract}

\begin{abstract}
Biological control of Ilex paraguariensis (A. St.-Hil.) pests with Beauveria sp.. The objective of this study was to verify the potentiality of producing Beauveria spore in agro-industrial waste, the maintenance of their viability after drying and storage tests and of testing its pathogenicity against insects of occurrence in mate culture: Thelosia camina e Hylesia sp. It was used Beauveria sp. strain LAG, isolated of a infected Thelosia camina caterpillar. The spore were produced in the blend of refused potatoes and sugar-cane bagasse (60-40\%) and used for the drying test which resulted in $76 \%$ of viability after $24 \mathrm{~h} / 35^{\circ} \mathrm{C}$, with concentrations of more of $10^{9}$ spore. $^{-1}$ of the material after storage at room temperature for 60 days. The experiments of pathogenicity resulted in death rates which ranged from 15.9 to $97 \%$, depending on the form of application (immersion or spraying), the used concentration (suspensions of $10^{8}$ to $10^{5}$ spore. $\mathrm{mL}^{-1}$ or suspension of macerate form infected caterpillars with the fungus), being these applications done in vitro or in the field. This study allowed to verify and confirm the pathogenicity of the strain Beauveria sp. - LAG on the lepidopteran on larval phase, as Thelosia camina and Hylesia sp.; which can be use as a possible biological control agent for the culture of mate.

Keywords: Beauveria sp.; biological control; caterpillars; mate.
\end{abstract}

\section{INTRODUÇÃO}

A erva-mate é uma importante cultura no Brasil, na Argentina, no Paraguai e no Uruguai. Suas folhas são utilizadas como bebida na forma de mate ou chimarrão, como planta medicinal, para chás e como ingrediente de cosméticos (COELHO et al., 2007; LORENZI; MATOS, 2002; HEINRICHS; 
MALAVOLTA, 2001; MAZUCHOWSKI; JUNIOR; BRACHT, 2000). O produto da erva-mate é consumido em sua maior parte "in natura", na forma de chimarrão (RÜCKER et al., 2007; ESMELINDRO et al., 2002; MAZUCHOWSKI; RÜCKER, 1997; VALDUGA; FREITAS; REISMANN, 1997), reforçando a necessidade de obtenção de um produto livre de agrotóxicos (PENTEADO, 1995).

Entre as principais pragas que atacam essa cultura, encontram-se Thelosia camina Schaus lagarta da erva-mate - e Hylesia sp. - lagarta do cartucho da seda -, altamente vorazes e que aparecem em ervais nativos e plantados, causando grandes danos econômicos. Nos últimos anos foram constatados vários surtos de Thelosia camina em diversos municípios dos estados do sul do Brasil (PENTEADO, 1995; PENTEADO; IEDE, 2005).

Na cultura da erva-mate não é permitido o uso de agrotóxicos. Assim, o manejo integrado de pragas (MIP) apresenta-se como a melhor alternativa para o controle das pragas da erva-mate (RIBEIRO, 2005; MAZUCHOWSKI; RÜCKER, 1997; DIAZ, 1997; BOZZETTO, 1995; PENTEADO, 1995; KOBER; VARGAS, 1960).

O MIP usa diferentes métodos de controle para manter a população de insetos-praga em níveis que não provoquem danos econômicos à cultura, causando o menor dano possível para o meio ambiente (NARDO et al., 1998; PEREIRA et al., 1998; WHITTEN, 1996; MADRIGAL, 1996; CARDONA, 1995). Os insetos são considerados parte do sistema ecológico e são controlados de modo a não alterar o balanço ecológico, o qual deve ser mantido, para que novas pragas não ocorram. Dessa forma, conseguese diminuir drasticamente o número de aplicações de agrotóxicos com benefícios para a qualidade ambiental e do produto final, com reflexos diretos na qualidade de vida e saúde dos agricultores e do consumidor (PEREIRA et al., 1998).

A base do MIP é o controle biológico (PEREIRA et al., 1998), que pode ser definido segundo Gallo et al. (2002) como sendo o controle de pragas feito por meio de inimigos naturais, que são os organismos que mantêm os níveis da população de insetos em equilíbrio. Entre os principais patógenos utilizados no controle biológico estão os fungos entomopatogênicos, como Metarhizium e Beauveria (AZEVEDO, 1998; SOUSA, 1999). A patogenicidade de diferentes cepas de Beauveria bassiana foi testada para o controle da broca-da-erva-mate, obtendo-se mortalidades de 73\% (PAGLIOSA et al., 1994) e de $83 \%$ (LEITE et al., 1998). Soares et al. (1996) detectaram a presença de Metarhizium e Beauveria na broca-da-erva-mate (Hedypathes betulinus - Coleoptera: Cerambicidae) e Oliveira et al. (2002) estudaram a suscetibilidade de Oligonychus yothersi (Acari: Tetranychidae) ao fungo Beauveria bassiana em experimento in vitro. A detecção da ocorrência natural desse fungo também na lagarta-da-erva-mate Thelosia camina abriu perspectivas de sua utilização como agente para controle biológico dessa praga (SILVA et al., 1998).

Nesse contexto, os objetivos deste trabalho foram verificar a potencialidade de produção de esporos de Beauveria sp.-LAG em resíduos agroindustriais, a manutenção da viabilidade dos esporos após testes de secagem e armazenamento na temperatura ambiente e, por fim, testar a influência das formas de aplicação e concentração dos esporos na ação e patogenicidade sobre as pragas da erva-mate Thelosia camina e Hylesia sp., em experimentos in vitro e em campo.

\section{MATERIAL E MÉTODOS}

\section{Microrganismos e produção de esporos}

As cepas de Beauveria sp. denominadas de LAG e ARR foram cedidas gentilmente pela Embrapa Florestas, Curitiba, sendo que a cepa LAG foi isolada a partir de uma lagarta infectada de ervamate. As cepas de Beauveria bassiana CG 152 e CG 61 foram cedidas gentilmente pelo CENARGEN Embrapa, Brasília. As cepas estão depositadas no cepário do Laboratório de Processos Biotecnológicos da UFPR. As cepas foram mantidas em tubos de ensaio contendo ágar batata dextrose (BDA) inclinado, com repique a cada seis meses.

Os esporos do fungo Beauveria sp.-LAG foram produzidos por fermentação no estado sólido, tendo como substrato a mistura de batata-refugo e bagaço de cana-de-açúcar na proporção de 60 e $40 \%$, respectivamente, com granulometria entre 2 a $0,8 \mathrm{~mm}$. A taxa de inóculo foi de $10^{7}$ esporos.g $\mathrm{g}^{-1} \mathrm{de}$ substrato seco; $\mathrm{pH}$ inicial do substrato de 6,0 ; incubação a $26^{\circ} \mathrm{C}$ por 10 dias. A suspensão de esporos foi obtida pela adição de água destilada ao material fermentado, com agitação por 5 minutos e filtração em malha de nylon $200 \mu \mathrm{m}$. A contagem do número de esporos foi realizada em câmara de Neubauer, com 
posterior diluição da suspensão a 5,6×10 $0^{7}$ esporos. $\mathrm{mL}^{-1}$ (DALLA SANTA et al., 2005; DALLA SANTA et al., 2004).

\section{Secagem do material fermentado, vida de prateleira e escalonamento da produção}

$\mathrm{O}$ material fermentado foi seco sob três condições: estufa a $35^{\circ} \mathrm{C}$; sílica-gel e circulação de ar forçado à temperatura ambiente. Após a secagem, o material fermentado foi utilizado para estudos de viabilidade.

$\mathrm{O}$ material fermentado e seco em estufa foi armazenado à temperatura ambiente e testes de viabilidade dos esporos foram realizados após 30, 60, 120 e 150 dias. Para os testes utilizou-se $1 \mathrm{~g}$ do material que foi diluído em $80 \mathrm{~mL}$ de água destilada esterilizada com $0,1 \%$ de Tween, com agitação por 30 minutos. Em seguida foram realizadas a diluição e o plaqueamento em profundidade, em meio BDA, incubação a $26^{\circ} \mathrm{C}$ e contagem das colônias após $48-72 \mathrm{~h}$.

$\mathrm{O}$ escalonamento da produção foi realizado com a mistura de batata-refugo e bagaço de cana-deaçúcar $(60 / 40 \%)$. Os estudos foram realizados com 20, 50, 100 e $200 \mathrm{~g}$, e as condições de fermentação foram as mesmas descritas anteriormente.

\section{Delineamento experimental}

O delineamento experimental foi inteiramente casualizado para todos os ensaios, com 5 repetições para os tratamentos dos experimentos in vitro e com 6 repetições para o bioensaio em campo. Os estudos de patogenicidade foram realizados com 5 lagartas para cada cepa de fungo testada, e os bioensaios do fungo sobre Hylesia sp. foram conduzidos com 20 lagartas por tratamento. Os experimentos com Thelosia camina in vitro e em campo foram realizados com 10 e 20 lagartas por unidade experimental, respectivamente. Os resultados foram analisados estatisticamente pelo programa MSTAT (Michigan State University). Foi aplicado o teste de Bartlet para análise da variância e o teste de Tukey a 5\% de probabilidade para a comparação de médias.

\section{Coleta das lagartas}

As coletas foram realizadas em uma área de erval misto, parte cultivada próxima à área nativa, no município de Pinhão, próximo ao Alagado de Foz do Areia, a $70 \mathrm{~km}$ de Guarapuava, que apresenta tipos climáticos Cfb e Cfa (classificação de Köppen), precipitação média anual de 1.700 a 2.000 mm, com médias térmicas anuais de 16 a $18{ }^{\circ} \mathrm{C}$. As lagartas foram trazidas ao laboratório e utilizadas para os ensaios in vitro e em campo. Para os experimentos in vitro, as lagartas Thelosia camina e Hylesia sp. foram coletadas durante os meses de novembro e dezembro de 2001. Para o experimento em campo, foi realizada uma terceira coleta em fevereiro de 2002. As lagartas coletadas em diferentes épocas apresentavam diferentes tamanhos. Dessa forma, a fim de verificar o ínstar das lagartas, elas foram separadas em uma população-base, que não foi submetida aos experimentos e foi cultivada no laboratório, com acompanhamento de seu desenvolvimento e contagem das mudanças de ínstar, fase de pré-pupa e de pupa. A outra parte da população das lagartas foi utilizada para os experimentos.

\section{Patogenicidade de cepas de Beauveria sp. sobre Thelosia camina}

Este estudo preliminar foi realizado com a finalidade de constatar a patogenicidade de quatro cepas de Beauveria bassiana (LPB, ARR, CG 152 e CG 61) em lagartas de erva-mate da espécie Thelosia camina. Suspensões de esporos de cada cepa foram produzidas em BDA, com concentrações ajustadas em $10^{8}$ esporos. $\mathrm{mL}^{-1}$. Em seguida, as lagartas ( $4^{\circ}$ ínstar de desenvolvimento) foram imersas na suspensão de esporos de cada cepa por 5 segundos, colocadas em placas de Petri e observadas diariamente, a fim de verificar a ação e extrusão do fungo.

\section{Pulverização de Beauveria sp.-LAG sobre Hylesia sp.}

Diferentes dosagens de esporos foram testadas: $10^{5}, 10^{6}, 10^{7} \mathrm{e} 10^{8}$ esporos. $\mathrm{mL}^{-1} \mathrm{e}$ a testemunha. Cada tratamento recebeu a pulverização de $1 \mathrm{~mL}$ da suspensão com a respectiva concentração de esporos. $\mathrm{Na}$ testemunha foi pulverizado $1 \mathrm{~mL}$ de água estéril. As lagartas se encontravam no $1^{\circ}$ e $2^{\circ}$ ínstares de desenvolvimento. 


\begin{abstract}
Alimentação, mortalidade e extrusão do fungo
As folhas de erva-mate foram coletadas semanalmente e guardadas à temperatura de $4{ }^{\circ} \mathrm{C}$, embaladas em sacos plásticos para não ficarem desidratadas. As lagartas foram colocadas em vidros fechados na parte superior com gaze e alimentadas com folhas de erva-mate. A troca das folhas e a limpeza dos frascos foram realizadas a cada dois dias. O experimento foi conduzido durante 10 dias à temperatura ambiente, com observação diária da mortalidade. As lagartas mortas foram passadas por uma solução de álcool $70 \%$ e por mais duas vezes em água estéril. Em seguida foram colocadas em câmara úmida, incubadas em estufa a $26^{\circ} \mathrm{C}$, para verificar a extrusão do fungo, ou seja, aparecimento do micélio e posterior esporulação na parte externa do corpo do inseto. A câmara úmida consistiu de uma placa de Petri contendo fina camada de algodão coberta por papel-filtro umedecido.
\end{abstract}

\title{
Macerado de lagartas infectadas por Beauveria sp.- LAG sobre Hylesia sp.
}

As lagartas infectadas por Beauveria sp.-LAG que apresentaram extrusão e crescimento do fungo em câmara úmida, provenientes do experimento anterior, foram trituradas com água estéril para produzir o macerado de lagartas. A aplicação desse macerado foi testada sob duas formas de aplicação: imersão das lagartas no macerado durante 5 segundos e pulverização de $1 \mathrm{~mL}$ do macerado sobre as folhas de erva-mate onde estavam as lagartas. Foi feita também a pulverização de $1 \mathrm{~mL}$ de água estéril nas testemunhas. As lagartas se encontravam no $1^{\circ}$ e $2^{\circ}$ ínstares de desenvolvimento.

\section{Bioensaio in vitro e em campo com Beauveria sp. sobre Thelosia camina}

Os ensaios com lagartas Thelosia camina foram realizados com esporos de Beauveria sp. obtidos do material fermentado seco e armazenado durante 120 dias à temperatura ambiente $\left( \pm 22{ }^{\circ} \mathrm{C}\right)$. A suspensão de esporos foi obtida pela adição de água destilada ao material fermentado, com agitação manual por 5 min. e filtração em malha de nylon de $200 \mu \mathrm{m}$. Uma amostra da suspensão foi utilizada para análise da viabilidade, que foi de $1,96 \times 10^{5}$ esporos. $\mathrm{mL}^{-1}$.

A suspensão de esporos foi testada sob duas formas de aplicação: por imersão na suspensão de esporos do fungo por 5 segundos e por pulverização, que foi feita utilizando-se $3 \mathrm{~mL}$ da suspensão de esporos aspergida sobre as folhas de erva-mate onde estavam as lagartas. A testemunha foi imersa por 5 segundos em água destilada estéril. As lagartas encontravam-se no $3^{\circ}$ e $4^{\circ}$ ínstares de desenvolvimento.

O experimento em campo foi realizado em erval com sistema convencional de manejo e idade das plantas de dois anos, situado na localidade de Guabiroba, no município de Guarapuava. Cada unidade experimental foi composta por uma planta, sob a qual foi fixado um pedaço de tecido de 1 x $1,4 \mathrm{~m}$, com graxa nas bordas, a fim de isolar a área. As lagartas foram coletadas no município de Pinhão e mantidas no laboratório por dois dias. Em seguida foram levadas a campo para o experimento. As lagartas $\left(4^{\circ}\right.$ ínstar) foram distribuídas nas plantas, onde rapidamente se dispersaram sob as folhas. Após meia hora da distribuição das lagartas, realizou-se a pulverização de $30 \mathrm{~mL}$ da suspensão de esporos de Beauveria sp.LAG $\left(5,6 \times 10^{7}\right.$ esporos. $\left.\mathrm{mL}^{-1}\right)$. Cada unidade-testemunha recebeu pulverização de $30 \mathrm{~mL}$ de água destilada.

\section{RESULTADOS E DISCUSSÃO}

\section{Secagem do material fermentado, vida de prateleira e escalonamento da produção}

Os resultados obtidos nos testes de secagem do material fermentado estão apresentados na tabela 1.

Tabela 1. Métodos de secagem do material fermentado por Beauveria sp.

Table 1. Drying methods of fermented material by Beauveria sp.

\begin{tabular}{lcc}
\hline Ensaio & Tempo (horas) & Viabilidade após a secagem (\%) \\
\hline Estufa $\left(35^{\circ} \mathrm{C}\right)$ & 24 & 76 \\
Circulação de ar & 72 & 40 \\
Sílica-gel & 48 & 70 \\
\hline
\end{tabular}

O tempo para secagem completa do material variou de 24 a 72 h entre os métodos testados. A maior viabilidade dos esporos (76\%) e o menor tempo (24 h) ocorreram na estufa com circulação de ar.

Os resultados (Figura 1) apontam para a manutenção de viabilidade dos esporos durante 90 dias de armazenamento à temperatura ambiente em concentração superior a $10^{9}$ esporos. $^{-1}$ do material (Base Seca). 
Após esse tempo, a viabilidade decresceu para valores inferiores a $10^{6}$ esporos. $\mathrm{g}^{-1}$. O escalonamento da produção demonstrou ser viável para obter material fermentado para realização dos experimentos.

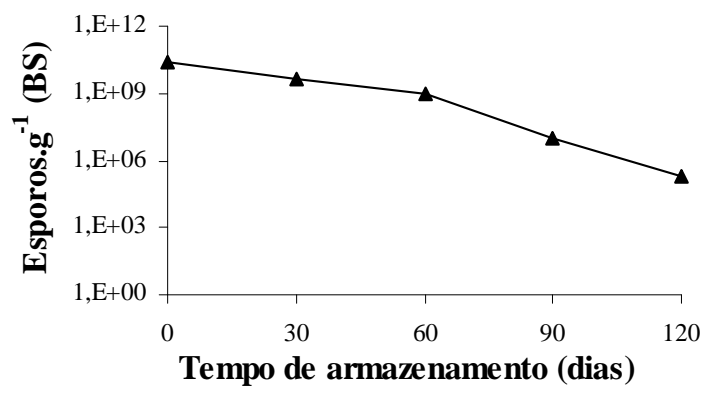

Figura 1. Viabilidade de esporos de Beauveria sp. armazenados à temperatura ambiente.

Figure 1. Spore viability of Beauveria sp. stored at room temperature.

\section{Patogenicidade de Beauveria sp. sobre Thelosia camina}

As cepas LPB e CG 61 de Beauveria apresentaram maior ação patogênica sobre as lagartas de erva-mate. Já as cepas ARR e CG 152 tiveram uma menor ação e extrusão do fungo sobre as lagartas. Uma diferença no nível de patogenicidade entre diferentes cepas de Beauveria também foi observada por Kmitowa et al. (1995), os quais, após estudarem 36 cepas de Beauveria bassiana de diferentes origens geográficas e diferentes hospedeiros frente a várias espécies de insetos, concluíram que cepas nativas tiveram ação mais efetiva. Diante desse fato, optou-se por utilizar uma variedade nativa de Beauveria sp. para os próximos ensaios.

\section{Pulverização de Beauveria sp.-LAG sobre Hylesia sp.}

Comparando-se os resultados apresentados na figura 2 entre os tratamentos no décimo dia do bioensaio, observou-se que a concentração de $10^{8}$ esporos. $\mathrm{mL}^{-1}$ propiciou $49 \%$ de mortalidade, enquanto que com as dosagens menores, de $10^{7}, 10^{6} \mathrm{e} 10^{5}$ esporos. $\mathrm{mL}^{-1}$, e com a testemunha foram obtidas 15,10 , 9 e $5 \%$ de mortalidade, respectivamente.

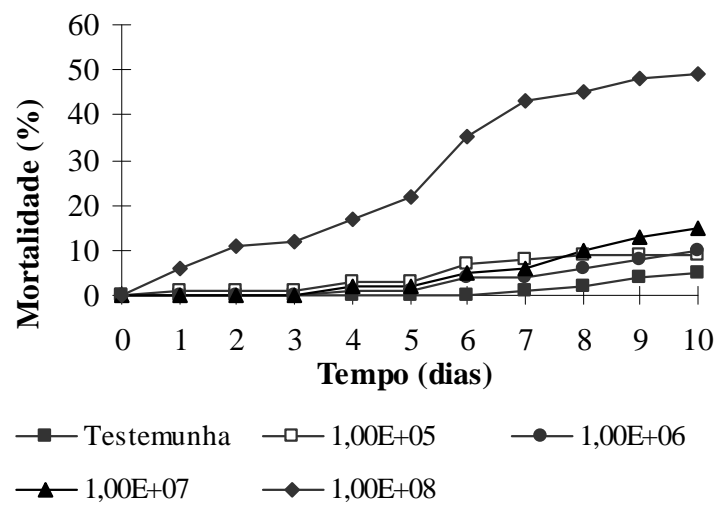

Figura 2. Pulverização de diferentes concentrações de esporos.mL $\mathrm{m}^{-1}$ de Beauveria sp.-LAG sobre Hylesia sp.

Figure 2. Spore pulverization of Beauveria sp. -LAG with different concentrations on Hylesia sp.

No decorrer do experimento $\left(5^{\circ}, 6^{\circ}\right.$ e $7^{\circ}$ dias), observaram-se lagartas de coloração esbranquiçada, semelhante ao que foi observado com a extrusão do fungo em câmara úmida nas lagartas mortas, assim como a presença de exúvias com a mesma coloração. A mortalidade observada foi menor do que o número de lagartas que apresentaram essa característica, especialmente do gênero Hylesia, que estavam visivelmente sob a ação do fungo: essas lagartas perdiam o hábito gregário e sua alimentação diminuiu. Assim, a inoculação pode ter um efeito que não se traduz pela morte da lagarta no prazo de 10 dias, mas talvez em uma alteração no seu comportamento. 
Os dados apresentados na tabela 2 demonstram que a dosagem de $10^{8}$ esporos. $\mathrm{mL}^{-1}$, no $7^{\circ}$ dia, ocasionou uma grande mortalidade, com diferença estatística dos outros tratamentos, que não diferiram entre si $(\mathrm{p}<0,05)$. No $10^{\circ}$ dia, o tratamento de $10^{8}$ esporos. $\mathrm{mL}^{-1}$ diferiu dos outros tratamentos, enquanto que os tratamentos de $10^{7}, 10^{6}$ e $10^{5}$ esporos. $\mathrm{mL}^{-1}$ não diferiram entre si. Entretanto, a dosagem de $10^{7}$ esporos. $\mathrm{mL}^{-1}$ diferiu da testemunha, e as duas dosagens menores, não $(\mathrm{p}<0,05)$.

Tabela 2. Mortalidade de lagartas Hylesia sp. nos dias 7 e 10 após pulverização de diferentes concentrações de esporos. $\mathrm{mL}^{-1}$ de Beauveria sp.-LAG.

Table 2. Hylesia sp. caterpillars mortality at day 7 and 10 after different concentrations of Beauveria sp.-LAG spore pulverization.

\begin{tabular}{lcc}
\hline \multirow{2}{*}{ Tratamentos } & \multicolumn{2}{c}{ Dias } \\
\cline { 2 - 3 } & $\mathbf{7}$ & $\mathbf{1 0}$ \\
\hline Testemunha & $1 \mathrm{a}$ & $5 \mathrm{a}$ \\
$1,00 \mathrm{E}+05$ & $8 \mathrm{a}$ & $9 \mathrm{ab}$ \\
$1,00 \mathrm{E}+06$ & $4 \mathrm{a}$ & $10 \mathrm{ab}$ \\
$1,00 \mathrm{E}+07$ & $6 \mathrm{a}$ & $15 \mathrm{~b}$ \\
$1,00 \mathrm{E}+08$ & $43 \mathrm{~b}$ & $49 \mathrm{c}$ \\
\hline *Tratamentos seguidos de letras diferentes na mesma coluna são estatisticamente diferentes $(\mathrm{p}>0,05)$.
\end{tabular}

Confirmou-se que a dosagem é um fator importante na mortalidade do gênero Hylesia, ao utilizar-se a pulverização como forma de aplicação. Em experimentos anteriores também foi observada uma correlação entre aumento da mortalidade com dosagem desse mesmo fungo contra lagartas de Hylesia sp. (DALlA SANTA et al., 2004). Além disso, o efeito da forma de aplicação resultou em diferenças de mortalidade, tendo sido a imersão mais eficiente do que a pulverização, resultado semelhante ao obtido por Padin et al. (1996). Essas diferenças podem ser devido ao fato de que na pulverização ocorre uma fragmentação das gotas e consequentemente a dispersão dos esporos que não atingem totalmente o alvo, sendo carreadas para o limbo das folhas ou outros pontos distantes das lagartas. Como os fungos agem por contato, ocorre uma redução da eficiência, enquanto na imersão os esporos entram em contato direto com o corpo da lagarta, aumentando a eficiência.

\section{Macerado de lagartas infectadas por Beauveria sp.-LAG sobre Hylesia sp.}

Segundo os resultados apresentados na figura 3, verificou-se que, por imersão, o macerado proporcionou mortalidade de $94 \%$ já no $1^{\circ}$ dia do experimento, chegando a $97 \%$ no $5^{\circ}$ dia. A mortalidade por pulverização e da testemunha foi de $19 \%$ e $3 \%$, respectivamente, no $10^{\circ}$ dia do experimento. A diferença de mortalidade das lagartas em função da forma de aplicação possivelmente deve-se à maior concentração de esporos e possivelmente também em função da presença do micélio do fungo, que atingem o corpo das lagartas quando se aplica a imersão, conforme foi discutido no item anterior. Além disso, ao utilizar macerado não é possível controlar a concentração de esporos do fungo, o que pode acentuar os aspectos da aplicação. O macerado pode ter em sua composição, além dos esporos e micélio do fungo, outros microrganismos provenientes das lagartas, que podem interferir na mortalidade.

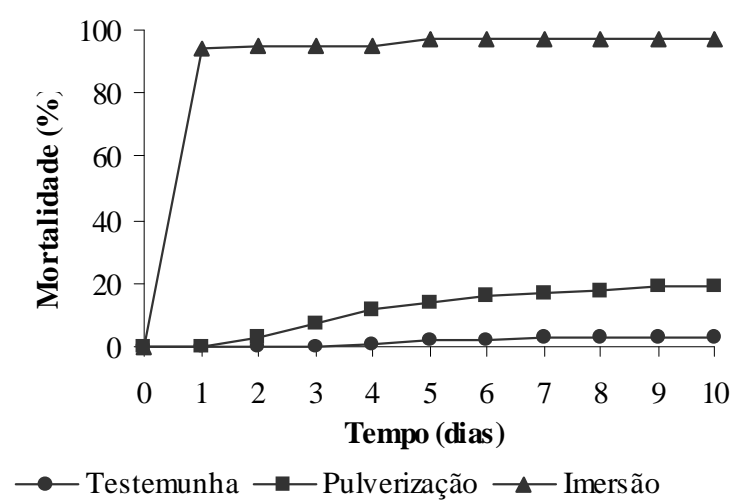

Figura 3. Mortalidade de Hylesia sp. frente à ação de macerado de lagartas infectadas por Beauveria sp.-LAG. Figure 3. Hylesia sp. mortality against macerate of caterpillars infected by Beauveria sp.-LAG. 
No $4^{\circ}$ e $10^{\circ}$ dias, foi observado que o tratamento por pulverização diferiu estatisticamente da testemunha $(p>0,05)$. É possível concluir que a mortalidade das lagartas está correlacionada com a suscetibilidade destas ao macerado, com a forma de aplicação e com a concentração dos esporos.

\section{Bioensaio in vitro e em campo com Beauveria sp. sobre Thelosia camina}

Comparando-se os resultados (Figura 4) entre os tratamentos no $10^{\circ}$ dia do bioensaio in vitro, observou-se que a mortalidade foi de $30 \%$, tanto por imersão como por pulverização, enquanto a testemunha apresentou $20 \%$. não tendo sido detectada diferença estatística entre os três tratamentos (p $<0,05)$. Neste experimento, foi utilizada uma metodologia um pouco diferente do que aquela relatada em experimentos anteriores (DALLA SANTA et al., 2004), pois a pulverização não foi feita sobre as lagartas, e sim sobre as folhas de erva-mate em que estavam as lagartas.

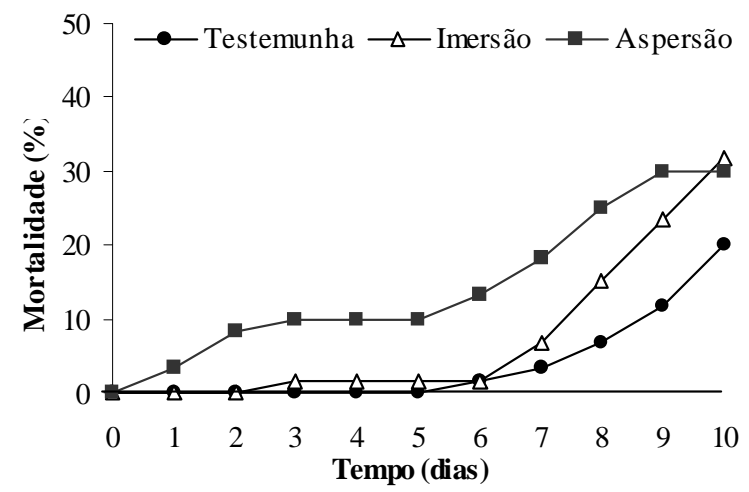

Figura 4. Bioensaio in vitro da aplicação de esporos de Beauveria sp.-LAG sobre Thelosia camina. Figure 4. Spore application of Beauveria sp.-LAG against Thelosia camina in essays in vitro.

Durante o experimento in vitro, o tratamento de pulverização resultou em maior mortalidade de lagartas, o que pode ter ocorrido em função de uma ação mais eficiente do fungo pela ingestão de esporos do fungo pelas lagartas. Além disso, optou-se por essa metodologia porque é o mais próximo do que ocorre no campo, ou seja, o agricultor pulveriza as plantas de erva-mate onde estão os insetos. Durante o experimento, observou-se que a maior parte das lagartas entrou em estágio de pré-pupa, e em seguida a próxima fase, a pupa. Isso pode ser explicado pelo fato de que insetos, quando sofrem algum estresse, tendem a encurtar as fases de vida na tentativa de antecipar a reprodução e garantir a continuidade da espécie. A inoculação pode ter um efeito que não se traduz pela morte da lagarta no prazo de 10 dias, mas por uma alteração no comportamento da lagarta, como diminuição da alimentação e perda do hábito gregário.

A mortalidade verificada ao final do experimento foi de 8,9\% para a testemunha e de $15,9 \%$ para o tratamento com pulverização de esporos de Beauveria sp.-LAG (p <0,05). Em todas essas lagartas ocorreu a extrusão do fungo, o que confirma sua ação patogênica. Neste estudo, foi observado que muitas lagartas não foram encontradas ao final do experimento. Sendo assim, é preciso alterar a metodologia a ser usada em bioensaios futuros em campo, de forma a melhorar o isolamento de cada unidade experimental.

\section{CONCLUSÕES}

Os resultados deste trabalho apontam para a potencialidade de produção de esporos de Beauveria sp. em resíduos agroindustriais, com manutenção da viabilidade em $76 \%$ após secagem em estufa a $35^{\circ} \mathrm{C}$ e com uma concentração de mais de $10^{9}$ esporos. $^{-1}$ do material após 60 dias de armazenamento à temperatura ambiente. Os testes de patogenicidade in vitro e em campo da cepa Beauveria sp.-LAG sobre as lagartas Thelosia camina e Hylesia sp. demonstraram a viabilidade de uso desse fungo como agente de controle biológico inserido em um programa de Manejo Integrado de Pragas na cultura da erva-mate. 


\section{REFERÊNCIAS}

AZEVEDO, J. L. Controle microbiano de insetos-pragas e seu melhoramento genético. In: MELO, I. S.; AZEVEDO, J. L. Pragas - Controle biológico. Jaguariúna: EMBRAPA, 1998. v. 1, p. 69-95.

BOZZETTO, D. J. Aspectos econômicos e sociais da cultura da erva-mate na região alta do Vale do Alto Taquari, Rio Grande do Sul, Brasil. In: WINGE, H.; FERREIRA, A. G.; MARRIATH, J. E. A. et al. Erva-mate: biologia e cultura no Cone-Sul. Porto Alegre: Ed. da Universidade, 1995. p. 207-213.

CARDONA, C. Entomologia y control de plagas: análisis y perspectivas para el futuro. Manejo integrado de plagas en cultivos y meio ambiente, Bogotá, Colômbia, v. 51, n.8, p.1-6, 1995.

COELHO, G. C.; RACHWAL, M. F. G.; DEDECEK, R. A.; CURCIO, G. R.; NIETSCHE, K.; SCHENKEL, P. E. Effect of light intensity on methylxanthine contents of Ilex paraguariensis A. St. Hil. Biochemical Systematics and Ecology, Oxford, v. 35, n. , p. 75-80, 2007.

DALLA SANTA, H. S.; DALLA SANTA, O. R.; BRAND, D.; VANDENBERGHE, L. P. S.; SOCCOL, C. R. Spore production of Beauveria bassiana from agro- industrial residues. Brazilian Archives of Biology and Technololy, Curitiba, v. 48, p. 51-60, 2005.

DALLA SANTA, H. S.; SOUSA, N. J.; BRAND, D.; DALLA SANTA, O. R.; PANDEY, A.; SOBOTKA, M.; PACA, J.; SOCCOL, C. R. Conidia production of Beauveria sp. by solid-state fermentation for biocontrol of Ilex paraguariensis caterpillars. Folia Microbiologica, Praha, v. 49, p. 337-496, 2004.

DIAZ, F. C. Y. Perspectivas del manejo integrado de plagas en yerba mate. In: CONGRESSO SULAMERICANO DA ERVA-MATE; II REUNIÃO TÉCNICA DO CONE SUL SOBRE A CULTURA DA ERVA-MATE, 1., 1997; Curitiba. Anais... Colombo: EMBRAPA, Centro Nacional de Pesquisa de Florestas, 1997. p. 371-390.

ESMELINDRO, M. C.; TONIAZZO, G.; WACZUK, A.; DARIVA, C.; OlIVEIRA, D. de. Caracterização físico-química da erva mate: Influência das etapas do processamento industrial. Ciência Tecnologia de Alimento, Campinas, v. 22, n. 2, p. 193-204, Maio/Agosto, 2002.

GALlO, D.; NAKANO, O.; SILVEIRA NETO, S.; CARVALHO, R. P. L.; de BAPTISTA, G. C.; BERTI FILHO, E.; PARRA, J. R. P.; ZUCCHI, R. A.; ALVES, S. B.; VENDRAMIM, J. D.; MARCHINI, L. C.; LOPES, J. R. S.; OMOTO, C. Entomologia Agrícola. Piracicaba: FEALQ, 2002. $920 \mathrm{p}$.

HEINRICHS, R.; MALAVOLTA, E. Mineral composition of a commercial product from mate-herb (Ilex paraguariensis St. Hil.). Ciência Rural, Santa Maria, v. 31, n. 5, p. 781-785, 2001.

KMITOWA, E.; POPOWSKA, N. E. The effect of culture methods on the pathogenicity of different strains and species of entompathogenic fungi. Polish Ecological Studies, Lomianki, v. 21, n. 1, p. 51-56, 1995.

KOBER, E.; VARGAS, E. Biologia e controle da "lagarta da erva-mate" (Thelosia camina Schaus,1920) (Lep.: Europtidae). Revista da Escola de Agronomia e Veterinária da Universidade do Rio Grande do Sul, Porto Alegre, v. 3, n. 1, p.7-35, 1960.

LEITE, M. S. P.; IEDE, E. T.; PENTEADO, S. R. C.; GRIGOLETTI, A. J.; CASTELLANO, C. Seleção de linhagens de Beauveria bassiana (Bals.) Vuill., em Hedypathes betulinus (Klug, 1825) praga da ervamate, Ilex paraguariensis ST. Hil.(Coleoptera, Cerambicidiae) em laboratório. In: CONGRESSO BRASILEIRO DE ENTOMOLOGIA, 17, 1998, Rio de Janeiro. Resumos... Rio de Janeiro: CIMP, UFRRJ, 1998. p. 767.

LORENZI, H.; MATOS, F. J. A. Plantas medicinais no Brasil: nativas e exóticas. São Paulo: Instituto Plantarum, 2002.

MADRIGAL, A. C. Programa MIP para plantaciones forestales. Boletin de Proteccion Forestal, Colombia, n. 1, p. 28-38, nov./dic. 1996. 
MAZUCHOWSKI, J. Z.; JUNIOR, A. M.; BRACHT, M. J. Normativos legais e as propriedades para pesquisa tecnológicas na cadeia produtiva da erva-mate. Curitiba: [s.n.], 2000.

MAZUCHOWSKI, J. Z.; RÜCKER, N. G. A. Erva-mate - prospecção tecnológica da cadeia produtiva. EMATER. Curitiba: SEAB - DERAL, 1997.

NARDO, E. A. B.; CAPALBO, D. M. F. Utilização de agentes microbianos de controle de pragas: mercado, riscos e regulamentações. In: MELO, I. S.; AZEVEDO, J. L. Pragas - Controle biológico. Jaguariúna: EMBRAPA, 1998. v. 1, p. 231-258.

OliVEIRA, R. C.; ALVES, L. F. A.; NEVES, P. M. O. J. Suscetibilidade de Oligonychus yothersi (Acari: Tetranychidae) ao fungo Beauveria bassiana. Scientia Agricola, Piracicaba, v. 59, n. 1, p. 187$189,2002$.

PADIN, S. B.; BELLO, G. M.; VASICEK, A. L. Potential bioinsecticida de hongos entomopatogenos de plagas en granos almacenados. Revista de la Facultad de Agronomia Universidad de Buenos Aires, La Plata, v. 15, n. 1, p. 1-7, 1996. Resumo.

PENTEADO, S. R. C. Principais pragas da erva-mate e medidas alternativas para o seu controle. In: WINGE, H.; FERREIRA, A. G.; MARRIATH, J. E. A. et al. Erva-mate: biologia e cultura no Cone-Sul. Porto Alegre: Ed. da Universidade, 1995. p. 109-120.

PENTEADO, S. R. C.; IEDE, E. T. Cultivo da Erva-Mate. Embrapa Florestas Sistemas de Produção, 1; Versão Eletrônica, Nov./2005. Disponível em: <http://sistemaproducao.cnptia.embrapa.br/FontesHTML/Erva-mate/CultivodaErvaMate.htm>. Acesso em: 16/08/2007.

PEREIRA, R. M.; ALVES, S. B.; SOSA-GÓMEZ, D. R. Utilização de entomopatógenos no manejo integrado de pragas. In: ALVES, S. B. 1998, Controle microbiano de insetos. 2. ed. Piracicaba: FEALQ, 1998.

RIBEIRO, M. M.; SANTOS, H. R.; DIODATO, M. A. Patogenicidade do fungo entomopatogênico Beauveria bassiana (bals.) Vuill., em Hedypathes betulinus (Klug, 1825), praga da erva-mate, Ilex paraguariensis St. Hil. Revista do Setor de Ciências Agrárias, Curitiba, v. 13, n. 1-2, p. 229-231, 1994.

RIBEIRO, M. M. Influência da adubação nitrogenada na incidência de Gyropsylla spegazziniana (Hemiptera:Psyllidae) praga da erva-mate cultivada. 98. f. Tese (Doutorado em Engenharia Florestal) - Setor de Ciências Agrárias, Universidade Federal do Paraná, Curitiba, 2005.

RÜCKER, N. G. A.; MACCARI JUNIOR, A.; ROCHA JÚNIOR, W. F. Agronegócio da Erva-Mate no Estado do Paraná: Diagnóstico e perspectivas para 2003. 8 p. Disponível em: <http://www.seab.pr.gov.br/arquivos/File/deral/ervamate.pdf>. Acesso em: 16/08/2007.

SILVA, C. F.; PEDROSA-MACEDO, J. H.; SOUSA, N. J. CORREA, R. M.; VENSON, I.; TREFFLICH, K.; ANGELO, A. C. Infecção de Thelosia camina Schaus, 1920 (Lepidoptera, Eupterodiae) - "lagarta da erva-mate" por Beauveria sp. In: CONGRESSO BRASILEIRO DE ENTOMOLOGIA, 17. 1998, Rio de Janeiro. Resumos... Rio de Janeiro: CIMP. UFRRJ, 1998, p. 769.

SOARES, C. M. S.; IEDE, E. T.; SANTOS, H. R. Ocorrência natural dos fungos entomopatogênicos Beauveria bassiana e Metarhizium anisopliae sobre Hedypathes betulinus (Coleoptera: Cerambicidae). In: SIMPÓSIO DE CONTROLE BIOLÓGICO, 5., 1996. Foz do Iguaçu. Resumos... Foz do Iguaçu: [s.n.], 1996. p. 403.

SOUSA, N. J. Aspectos biológicos, ecológicos de miroorganismos. In: SEMINÁRIO : POSSIBILIDADES DEL CONTROL BIOLÓGICO EN PLANTACIONES FORESTALES DE COLOMBIA - PROGRAMA DE PROTECCION FORESTAL. Memorias... Santafé de Bogotá: CONIF - MINAMBIENTE - BIRF, 1999. 
VALDUGA, E.; FREITAS, R. J. S. de, REISMANN, C. B.; NAKASHIMA, T. Caracterização química da folha de Ilex paraguariensis St. Hil. (erva-mate) e de outras espécies utilizadas na adulteração do mate. Boletim do Centro de Pesquisa e Processamento de Alimentos, Curitiba, v. 15, n. 1, p .25-36, 1997.

WHITTEN, M. J. Integrating biological control into IPM programs. In: SIMPÓSIO DE CONTROLE BIOLÓGICO, 5., Foz do Iguaçu, 1996. Anais... Foz do Iguaçu: EMBRAPA, CNPSo, COBRAFI, 1996. p. 1-21. 